do find an abundance of planets, the Kantian revolution will not be complete. The new planets might be exactly the same size as Earth and orbit their stars at the same distance, and although an astronomer might be willing to call such a thing Earth-like, most people will look for more. Does it have liquid water? Does it have a recognizable atmosphere? And, inevitably, could it - does it - support life?

Finding the answers to these questions will take decades. Kepler and COROT are merely steps along the way. In the meantime, we can take solace from Kant: "I am of the opinion that it is not particularly necessary to assert that all planets must be inhabited. However, at the same time it would be absurd to deny this claim with respect to all or even to most of them."

It took nearly 250 years to prove him mostly right the first time. With a little luck and perseverance - and, as Boss shows, a lot of work by astronomers around the world - the final step may just come a little faster.

Michael Brown is professor of planetary astronomy in the Division of Geological and Planetary Sciences, California Institute of Technology, Pasadena, California 91125, USA. e-mail:mbrown@caltech.edu

See www.nature.com/astro09 for more on the International Year of Astronomy.

\title{
Charting the heavens from China
}

\section{The Dunhuang Star Chart \\ The British Library, London \\ Until 18 August 2009}

Along the ancient trade route of the Silk Road connecting China and the West, the Mogao Caves honeycomb the Mingsha Hill some 25 kilometres southeast of Dunhuang, a desert town in Gansu province. Excavated between the fourth and fourteenth centuries, the caves were Buddhist shrines and temples where travellers prayed for the success of their journeys.

In 1900, the Taoist priest Wang Yuanlu propelled the Mogao Caves to the status of an archaeological crown jewel when he stumbled upon a hidden library in Cave 17. It contained more than 40,000 manuscripts on a myriad of subjects, from religion, history, art and literature to mathematics, medicine and economics. The documents had been sealed in the cave by Buddhist monks in the eleventh century.

Among the manuscripts was an exquisite star chart. It shows the entire sky as visible from China, skilfully drawn by hand in red and black inks onto a fine, fourmetre-long paper scroll. In 1907, archaeologist Marc Aurel Stein took the chart and more than 7,000 other cave manuscripts to the British Museum in London.

Dated to between 649 and $684 \mathrm{AD}$, the chart is the oldest extant graphical star atlas in the world, explains Susan Whitfield,

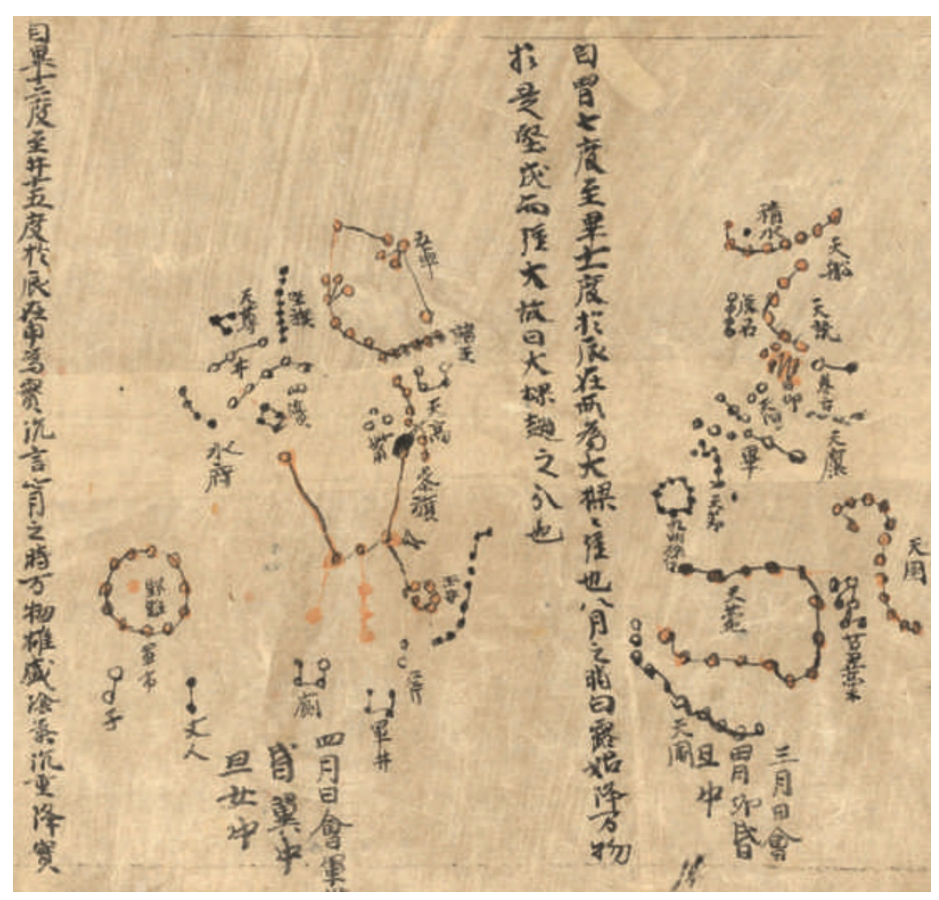

The three stars that make up the familiar 'belt' of Orion are recognizable in this panel from the seventh-century star chart discovered near Dunhuang, China. a latitude of $34^{\circ} \mathrm{N}$, possibly from the Imperial Observatory in Chang'an (present-day Xi'an) or another site in Luoyang.

The atlas shows 1,339 stars arranged in 257 groups, or asterisms, two of which resemble the constellations of the Big Dipper and Orion. It includes faint stars that are difficult to see with the naked eye, and several in the Southern Hemisphere. The styles of the dots differentiate the three schools of astronomical tradition established during the Warring States period (476-221 BC), each of which adopted alternative names and descriptions for the star groups.

The positions of the brightest stars are surprisingly accurate to within a few degrees, says astronomer Jean-Marc Bonnet-Bidaud of the CEA, the French Atomic Energy Commission, who has studied the atlas together with Whitfield and Françoise Praderie of the Paris Observatory (J.-M. Bonnet-Bidaud, F. Praderie and S. Whitfield J. Astron. Hist. Herit. 12, 39-59; 2009). Stars near the celestial horizon are drawn using a cylindrical projection, in which meridians are mapped to equally spaced vertical lines, and circles of latitude are mapped to horizontal lines. The circumpolar region uses an azimuthal projection, preserving the directions of the stars from a central point. These methods are still used in geographical mapping today.

Ancient Chinese astronomers divided the celestial circle into 12 sections to follow the orbit of Jupiter, known as the Year Star in China, which loops the Sun about every 12 years. The Jupiter cycle is also the basis for the 12 months of the year that make up the Chinese calendar. On the Dunhuang chart, the text accompanying each star map names that region of sky, the astrological predictions associated with it and the states of the Chinese empire thought to be influenced by that division.

The chart may have been reproduced from an earlier atlas by tracing it on to fine paper. It has no coordinate grid, and shares wording with another traditional astronomical text, Yue Ling, or Monthly Ordinances, which has been dated to around 300 вс. Yet it remains the earliest-surviving detailed map of the entire northern sky, pre-dating others by several centuries. Older star maps described only part of the sky. The Book of Fixed Stars, an Arabic work written by the Persian astronomer Abd al-Rahman al-Sufi (903-986 AD), displays individual constellations but gives no information on their relative positions. The 
oldest-known star chart in Europe is the Vienna manuscript. Dated to $1440 \mathrm{AD}$, it shows only a limited number of stars in northern constellations, plotted in an azimuthal projection from the ecliptic pole.

The chart may have been used to consult the heavens to predict earthly events. Astronomy was an imperial science in ancient China, and court astronomers and astrologers created star charts from at least the fifth century вс. Chinese emperors sought celestial clues for political and warfare decisions, and the importance of divination led to an early precision in star catalogues.

But why was the chart kept in the Mogao Caves rather than in the imperial archive? "It remains a mystery," says Whitfield. A political and secret document, it may have served a military purpose rather than being a guide for travellers. When the Taoist priest discovered the hidden library, he could hardly have guessed that he was opening the door to a world of such fascinating antiquity.

Jane Qiu writes for Nature from Beijing.

e-mail: jane@janeqiu.com

See www.nature.com/astro09 for more on the International Year of Astronomy.

\section{Superstition challenged}

\author{
Grimoires: A History of Magic Books \\ by Owen Davies \\ Oxford University Press: 2009. 384 pp. \\ $£ 14.99, \$ 29.95$
}

You might expect to find grimoires collections of magic spells, recipes and charms - on the shelves of medieval mystics or in the pages of Harry Potter books. But as social historian Owen Davies shows, they are not confined to history and fantasy.

In the 1960s, for example, the German Lutheran minister Kurt Koch waged war against what he called the "flood of magical conjuration which washes the Alps", namely the superstitions he had found across southern Germany, Austria and Switzerland. To his dismay, such beliefs were promoted in cheap, mass-produced grimoires such as The Sixth and Seventh Books of Moses - a title that had circulated in Europe since at least the eighteenth century.

Two contrasting positions in the modern view of grimoires are personified in another dispute in Germany in the 1950s. On one side was Johann Kruse, a schoolteacher who had seen many people, including his own mother, accused of witchcraft in rural SchleswigHolstein in northern Germany. Like Koch, he wanted to see such beliefs banished. In 1950 Kruse founded the Archive for the Investigation of Contemporary Witchcraft Superstition, and he published the exposé Witches Among Us? the following year. In 1956, he successfully sued the publisher Planet-Verlag for selling a cheap version of The Sixth and Seventh Books of Moses. Kruse's campaign seems at first like a noble attempt to combat ignorance and deceit by targeting publishers who were exploiting the gullibility of uneducated people. But such efforts often had moralistic overtones, akin to attempts to suppress pulp fiction in favour of more 'improving' literature.

On the other side of this debate were academic folklorists such as Will-Erich Peuckert, who testified for the defence against Kruse and felt that folk beliefs were a valid part of

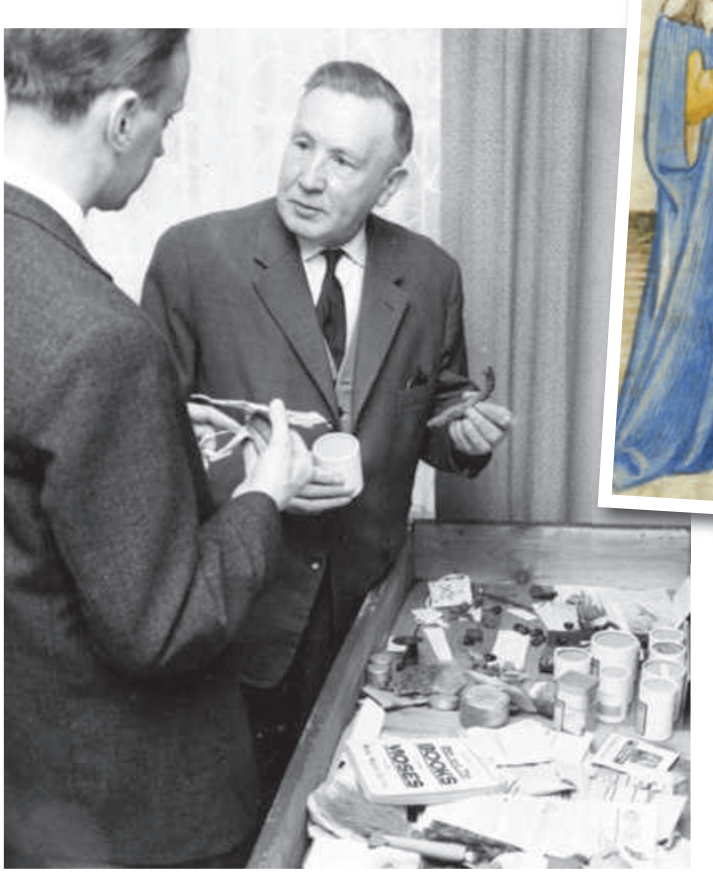

Johann Kruse's 1950s campaign against superstition and sorcery targeted books conveying such beliefs (inset, right).

cultural tradition. Davies is refreshingly neutral, content with wry asides that leave no doubt about his views on these childish compendiums of 'magic'.

But grimoires weren't always ridiculous. Some collections of recipes and tricks from antiquity, such as the Stockholm and Leiden papyri - discovered in the 1820s and probably made in Egypt in the third century AD - provide a valuable window on the technologies of their age, describing the preparation of medicines, pigments, dyes and metals. And some 'magic' books - such as Giambattista Della Porta's Natural Magic (1558), which describes a camera obscura - are scientific treatises on mathematics and optics. These claim an allegiance to magic only because of the Neoplatonic view that natural magic is the mechanical system of nature, a web of hidden or occult forces.
In this regard, Davies's book disappoints. Despite offering an overview of magical tradition, he never really beds it into the history of ideas wherein magic occupies a valid prescientific role. One looks in vain for the sort of synoptic theses that motivate, for example, Keith Thomas's magisterial Religion and the Decline of Magic (Weidenfeld and Nicholson, 1971), or Norman Cohn's study of witchcraft and persecution, Europe's Inner Demons (Basic Books, 1975).

Most of all, there is no sense of why magical belief proves so tenacious when magic itself does not work. As anthropologist Bronisław Malinowski argued, magic ritualizes hope in an adverse world, so that one coincidental success cancels out countless failures. And as Thomas showed, religion encouraged magical belief even while competing and sometimes merging with folk superstitions. In the Middle Ages, many uneducated parish priests conducted services as arcane rituals, with an incomprehensible liturgy and the Eucharistic host wielded like a talisman or cure-all.

Magic has long been associated with experimental science, as made clear by Lynn Thorndike in his multi-volume survey of those two activities, published between 1923 and 1958. Technology often carried the suspicion of 